Borges de Moura, D. M., De Oliveira, R. M., De Oliveira, I. J., Ferreira Nascimento, D. T., Dos Santos Alves, W. (2018): "O uso de geotecnologias na análise morfométrica da alta bacia hidrográfica do ribeirão Santo Antônio, no município de Iporá-Goiás, Brasil”, GeoFocus (Artículos), no 21, p. 19-37. ISSN: 1578-5157 http://dx.doi.org/10.21138/GF.493

\title{
O USO DE GEOTECNOLOGIAS NA ANÁLISE MORFOMÉTRICA DA ALTA BACIA HIDROGRÁFICA DO RIBEIRÃO SANTO ANTÔNIO, NO MUNICÍPIO DE IPORÁ- GOIÁS, BRASIL
}

\author{
DERICK MARTINS BORGES DE MOURA ${ }^{1}$, RAQUEL MARIA DE OLIVEIRA ${ }^{2}$, \\ IVANILTON JOSÉ DE OLIVEIRA ${ }^{1}$, DIEGO TARLEY FERREIRA NASCIMENTO ${ }^{3}$ E \\ WELLMO DOS SANTOS ALVES ${ }^{2}$ \\ ${ }^{1}$ Instituto de Estudos Sócio-ambientais (IESA). Universidade Federal de Goiás. \\ Av. Esperança, s/n - Samambaia, Goiânia - GO, 74001-970, Brasil \\ derickmartins@hotmail.com, ivanilton.oliveira@gmail.com \\ ${ }^{2}$ Universidade Federal de Goiás, regional de Jataí, câmpus Cidade Universitária. \\ Rodovia BR 364, km 195, no 3800 Jataí - GO, 75801-615, Brasil \\ diraquelmo.oliveira@gmail.com, wellmo.alves@ifgoiano.edu.br \\ ${ }^{3}$ Instituto de Estudos Sócio-ambientais (IESA). Universidade Federal de Goiás. \\ Av. Esperança, s/n - Samambaia, Goiânia - GO, 74001-970, Brasil \\ diego.tarley@gmail.com
}

\section{RESUMO}

O presente trabalho utiliza geotecnologias para análise morfométrica da alta bacia hidrográfica do ribeirão Santo Antônio, que é a única fornecedora de água para abastecimento da cidade de Iporá, no centro-oeste do estado de Goiás, Brasil. Nesse estudo foram selecionados e aplicados vinte e oito parâmetros morfométricos para serem analisados com a finalidade de obter informações das características da bacia hidrográfica. Os resultados de alguns parâmetros, como a declividade (0$45 \%$ ), a amplitude altimétrica $(331 \mathrm{~m})$, o gradiente do canal principal $(11,4 \mathrm{~m} / \mathrm{km})$, a densidade hidrográfica $\left(1,40\right.$ canais $\left./ \mathrm{km}^{2}\right)$ e a sinuosidade do canal principal $(1,424 \mathrm{~km} / \mathrm{km})$ mostraram que a bacia não é propensa a inundações, mas tem alta capacidade de escoamento superficial de água. Essa característica é prejudicial à infiltração e posterior recarga hídrica do lençol freático, destacando a importância do planejamento e da gestão do uso da bacia para o abastecimento hídrico do município em questão.

Palavras chave: geotecnologias, análise morfométrica, bacia hidrográfica, recursos hídricos.

\section{ABSTRACT}

The present paper uses geotechnology for morphometric analysis of high hydrographic basin of Santo Antonio's river, which is the only source of water for the supply of Iporá city, in the state of Goiás, Brazil. On this study were selected and applied twenty eight morphometric parameters to be analyzed with the purpose of obtaining information of the characteristics of the hidrographic basin. The results of some parameters, such as slope $(0-45 \%)$, altimetric amplitude $(331 \mathrm{~m})$, main channel gradient $(11.4 \mathrm{~m} / \mathrm{km})$, hydrographic density $\left(1.40\right.$ hydrographic channels $\left./ \mathrm{km}^{2}\right)$ and the sinuosity of the main channel $(1,424 \mathrm{~km} / \mathrm{km})$ showed that the basin is not likely for inundations; 
Borges de Moura, D. M., De Oliveira, R. M., De Oliveira, I. J., Ferreira Nascimento, D. T., Dos Santos Alves, W. (2018): "O uso de geotecnologias na análise morfométrica da alta bacia hidrográfica do ribeirão Santo Antônio, no município de Iporá-Goiás, Brasil”, GeoFocus (Artículos), n² 21, p. 19-37. ISSN: 1578-5157 http://dx.doi.org/10.21138/GF.493

however, it has high superficial flowing capacity, because of the rugged terrain. This characteristic of the basin propitiates the superficial flowing of water being unfavorable to the infiltration and hydric reloading of the groundwater table. Therefore, the presented results are relevant to the management and planning of the use of water rate for the public supplying of Iporá city.

Key words: geotechnologies, morphometric analysis, hydrographic basin, hydric resources.

\section{Introdução}

A água é um recurso natural fundamental para a sobrevivência humana e o desenvolvimento da sociedade. Para tanto, o planejamento e a gestão desse recurso se faz essencial, para que seja assegurada sua disponibilidade - tanto em termos de quantidade quanto de qualidade - e de modo a evitar problemas desencadeados pela apropriação inadequada das bacias hidrográficas.

Nesse contexto temos a cidade de Iporá, situada no centro-oeste do estado de Goiás, cujo abastecimento público de água ocorre pela captação em um manancial de superfície, o ribeirão Santo Antônio, que passa próximo à zona urbana. Segundo Moura et al. (2017), o problema de escassez dos recursos hídricos para abastecimento da cidade de Iporá vem se manifestando com frequência devido ao aumento populacional, gerando uma maior demanda, ao mesmo tempo em que ocorre uma redução na oferta, devido às degradações ambientais na fonte produtora.

Christofoletti (1980) afirma que o estudo hidrológico e das características físicas de uma bacia hidrográfica tem aplicação em diversas áreas, mas principalmente na escolha de fontes para abastecimento de água para uma população. E, para facilitar o planejamento e utilização dos recursos hídricos no abastecimento público, pode-se utilizar a análise morfométrica das bacias hidrográficas. Esse tipo de análise é uma técnica muito importante para um melhor entendimento da dinâmica dos recursos hídricos, informação fundamental para o planejamento e gestão desse recurso, seja para o abastecimento humano ou para o desenvolvimento de suas atividades econômicas.

O estudo morfométrico de bacias hidrográficas se baseia na análise quantitativa das relações entre a fisiografia e a dinâmica hidrológica da bacia. A análise de parâmetros morfométricos tem grande importância nos estudos de bacias hidrográficas, por retratar o comportamento hidrológico, uma vez que é capaz de indicar a capacidade de armazenamento da água no solo ou o seu escoamento superficial. A análise morfométrica da alta bacia hidrográfica do ribeirão Santo Antônio pode subsidiar trabalhos futuros em relação a vários aspectos ambientais, principalmente no que se relaciona com a disponibilidade hídrica para abastecimento da cidade.

A utilização de ferramentas geotecnológicas contribui para a análise morfométrica de bacias hidrográficas, pois proporciona maior facilidade na obtenção dos resultados dos parâmetros morfométricos, extraídos de forma semi-automática a partir de derivações do Modelo Digital de Elevação (MDE) do terreno, que pode ser obtido por imagens geradas pelo Shuttle Radar Topography Mission (SRTM) ou outras fontes, em ambiente de Sistema de Informações Geográficas (SIG) . Os produtos SRTM são geralmente os mais utilizados em pesquisas científicas pelo fato de fornecerem cobertura de imagem para praticamente todo o planeta, por possuírem resolução que atende às escalas de 1:100.000 ou menores e serem disponibilizadas gratuitamente.

Desse modo, esse trabalho se vale de geotecnologias para obter um diagnóstico sobre os aspectos morfométricos da alta bacia hidrográfica do ribeirão Santo Antônio, com o intuito de produzir e disponibilizar informações de como os aspectos físicos do relevo condicionam a 
Borges de Moura, D. M., De Oliveira, R. M., De Oliveira, I. J., Ferreira Nascimento, D. T., Dos Santos Alves, W. (2018): "O uso de geotecnologias na análise morfométrica da alta bacia hidrográfica do ribeirão Santo Antônio, no município de Iporá-Goiás, Brasil”, GeoFocus (Artículos), no 21, p. 19-37. ISSN: 1578-5157 http://dx.doi.org/10.21138/GF.493

disponibilidade dos recursos hídricos da bacia fornecedora de água para captação, tratamento e abastecimento público da cidade de Iporá.

Além de contribuir na avaliação da potencialidade da bacia em produção e armazenamento de água, o presente trabalho se justifica por auxiliar na gestão dos recursos hídricos e no planejamento de atividades de prevenção da de água na bacia, pois além de fornecer o cenário de sua situação, os resultados obtidos podem servir de insumo para ações do poder público e da comunidade em geral para o desenvolvimento de práticas sustentáveis de ocupação da bacia e utilização dos recursos hídricos.

\section{Materiais e Métodos}

\subsection{Caracterização da área de estudo}

O ribeirão Santo Antônio é um afluente do rio Caiapó que, por sua vez, integra a bacia hidrográfica do rio Araguaia, um dos principais rios no interior do território brasileiro. A alta bacia do ribeirão Santo Antônio compreende toda seção à montante do ponto de captação de água, que é realizada pela empresa estatal Saneamento de Goiás S/A (SANEAGO). Está situada a noroeste do perímetro urbano de Iporá (GO), nas coordenadas UTM 22S N 8.182.000 a 8.198.000, e E 475.000 a 492.000, como pode ser verificado na Figura 1. Neste trabalho, a área de estudo será denominada pela sigla BHRSA, relativa à designação da bacia hidrográfica do ribeirão Santo Antônio.

Segundo o Instituto Mauro Borges de Estatísticas e Estudos Socioeconômicos - IMB (2014), o município de Iporá faz parte da região de planejamento denominada Oeste Goiano, e possui um território de 1.026,384 km². A BHRSA, por sua vez, abrange uma extensão de $127,062 \mathrm{~km}^{2}$, ou seja $12,37 \%$ da área total do município.

A cidade de Iporá está localizada a $216 \mathrm{~km}$ de Goiânia, capital do estado de Goiás, tendo como vias de acesso as rodovias GO-060, GO-174, GO-221 e GO-320. De acordo com estimativas do Instituto Brasileiro de Geografia e Estatística (IBGE, 2017), o município de Iporá apresenta uma população total estimada de 32.242 habitantes, sendo que a população urbana é estimada em 29.489 habitantes $(\sim 91 \%)$.

A altitude média do município é de $562 \mathrm{~m}$ acima do nível do mar, sendo que a cota mais elevada é de $888 \mathrm{~m}$ e, a mais baixa, de $379 \mathrm{~m}$. O município localiza-se no interior do bioma Cerrado, que possui extrema relevância por abrigar grande quantidade de nascentes de algumas das principais bacias hidrográficas brasileiras: a Araguaia/Tocantins, a do Paraná e a do São Francisco.

Segundo a classificação de Köeppen (1948), o clima na região é do tipo Aw - Clima tropical de savana, caracterizado por duas estações bem distintas: uma seca (abril a setembro) e outra chuvosa (outubro a março).

Segundo dados do posto pluviométrico 1651001 da Agência Nacional das Águas (ANA), instalado em Iporá, referentes ao período de 1974 a 2014 (40 anos), a média de precipitação anual é de $1.600,9 \mathrm{~mm}$. 
Borges de Moura, D. M., De Oliveira, R. M., De Oliveira, I. J., Ferreira Nascimento, D. T., Dos Santos Alves, W. (2018): "O uso de geotecnologias na análise morfométrica da alta bacia hidrográfica do ribeirão Santo Antônio, no município de Iporá-Goiás, Brasil”, GeoFocus (Artículos), no 21, p. 19-37. ISSN: 1578-5157 http://dx.doi.org/10.21138/GF.493

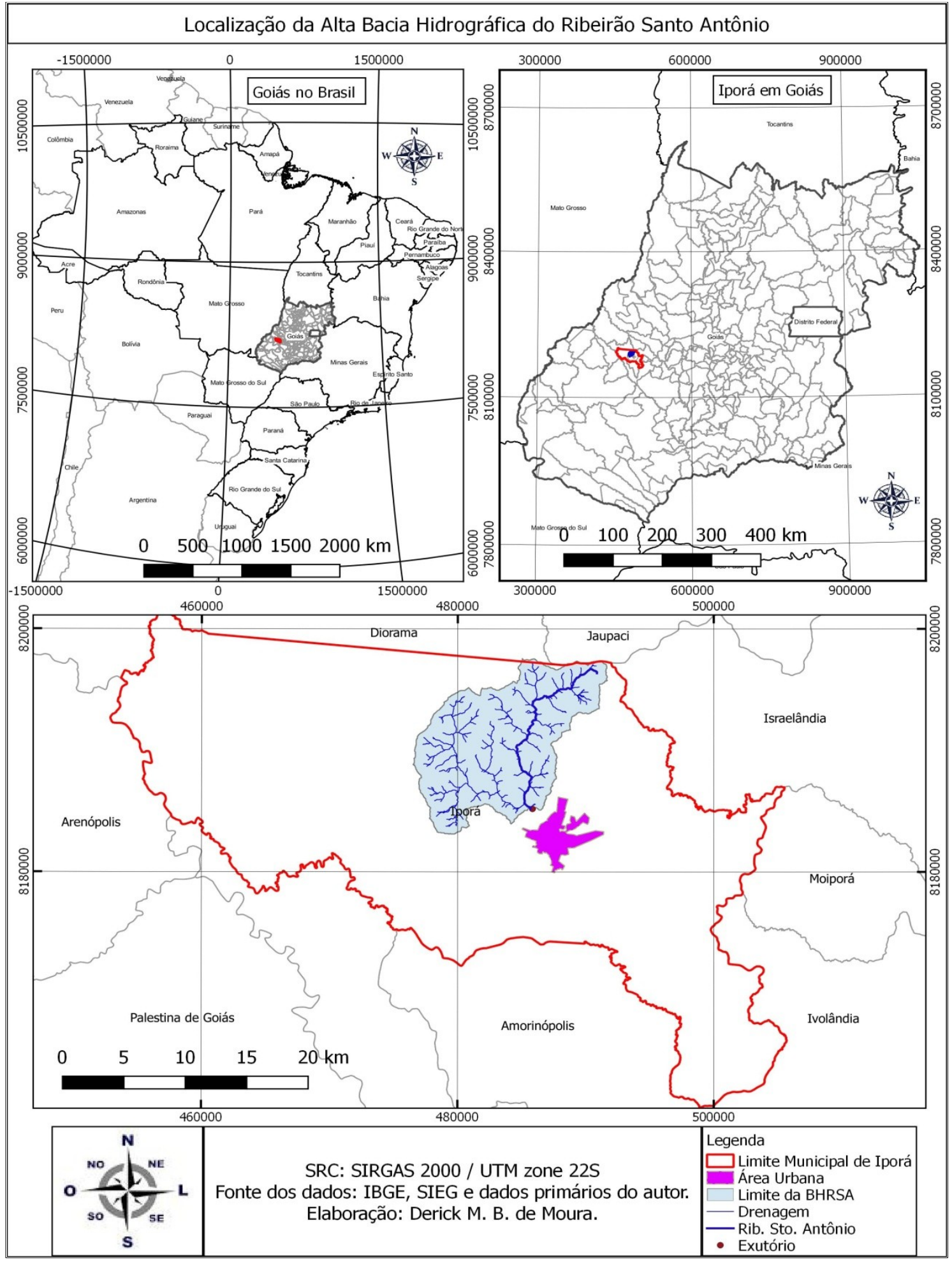

Figura 1: Localização da BHRSA 
Borges de Moura, D. M., De Oliveira, R. M., De Oliveira, I. J., Ferreira Nascimento, D. T., Dos Santos Alves, W. (2018): "O uso de geotecnologias na análise morfométrica da alta bacia hidrográfica do ribeirão Santo Antônio, no município de Iporá-Goiás, Brasil”, GeoFocus (Artículos), no 21, p. 19-37. ISSN: 1578-5157 http://dx.doi.org/10.21138/GF.493

Conforme indicado pelo gráfico da Figura 2, os meses mais chuvosos são representados por janeiro $(310,6 \mathrm{~mm})$ e dezembro $(298,8 \mathrm{~mm})$, ao passo que os meses de junho $(12,5 \mathrm{~mm})$, julho $(3,0 \mathrm{~mm})$ e agosto $(10,1 \mathrm{~mm})$ apresentam os menores valores médios de precipitação mensal. O período chuvoso, compreendido entre outubro e março, concentra $88 \%$ do total anual de chuvas, ao passo que o período de estiagem representa apenas $12 \%$.

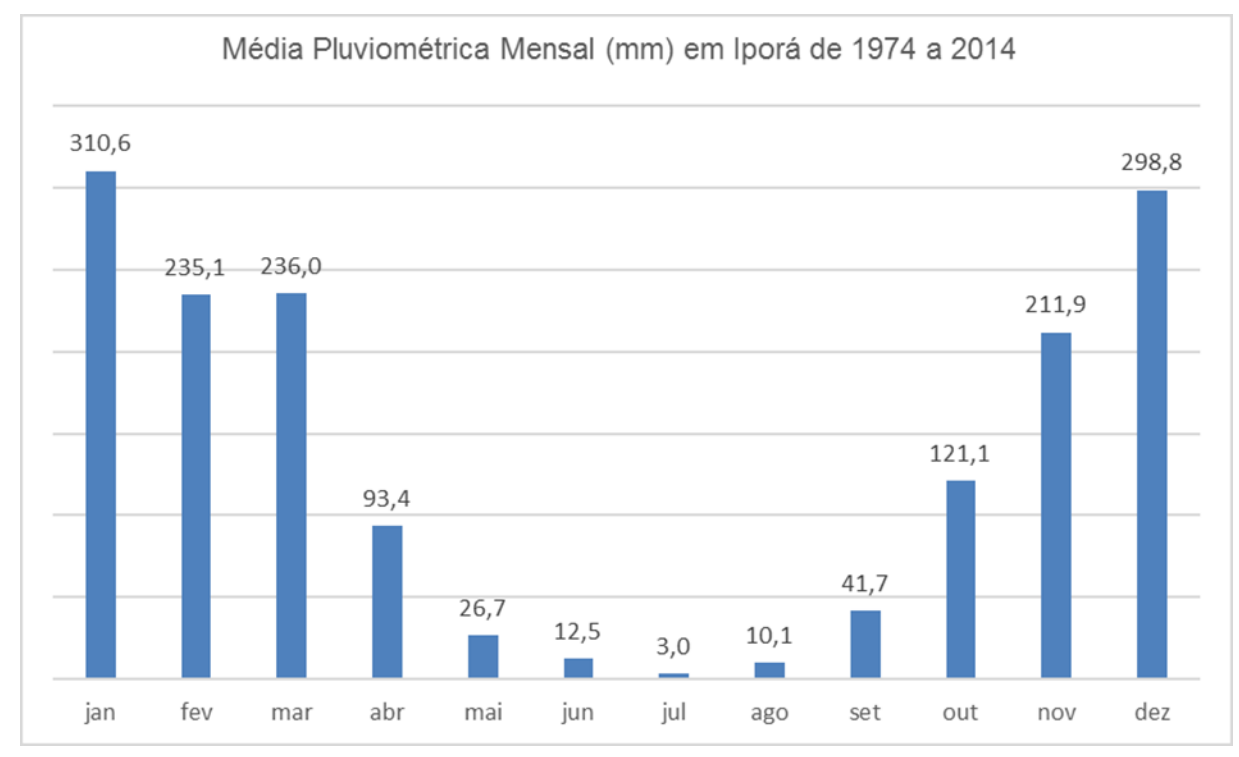

Figura 2: Média pluviométrica mensal em Iporá de 1974 a 2014

\subsection{Metodologia}

Para execução do trabalho foram utilizadas cenas de imagens do Banco de Dados Geomorfométricos do Brasil (TOPODATA, 2015), que consistem em variáveis morfométricas extraídas do Modelo Digital de Elevação (MDE) derivado do processamento de imagens do SRTM e refinamento da sua resolução original de 90 metros para $30 \mathrm{~m}$.

Para o processamento dos dados foi utilizado o software Quantum GIS (QGIS). O QGIS é um software de código aberto (gratuito). O programa é um projeto oficial da Open Source Geospatial Foundation (OSGeo). Funciona em Linux, Unix, Mac OSX, Windows e Android e suporta inúmeros formatos de vetores, rasters, bases de dados e funcionalidades (QGIS, 2018).

Os procedimentos metodológicos consistiram inicialmente na delimitação automática da bacia hidrográfica e na extração e classificação das drenagens da BHRSA, tendo sido utilizada a extensão Terrain Analysis Using Digital Elevation Models (TauDEM), contida no QGIS, que representa um conjunto de ferramentas que, com base no Modelo Digital de Elevação, permitem a delimitação de bacias hidrográficas e uma série de análises hidrológicas de maneira automática, rápida e objetiva. Após a delimitação foram obtidos os parâmetros morfométricos a serem analisados.

Todo o processo de delimitação se deu de forma automática, ficando a cargo do operador apenas a escolha do ponto definido como o exutório da bacia, que corresponde ao ponto de maior acúmulo de fluxo de água de toda a área, que neste trabalho foi o ponto de captação de água 
Borges de Moura, D. M., De Oliveira, R. M., De Oliveira, I. J., Ferreira Nascimento, D. T., Dos Santos Alves, W. (2018): "O uso de geotecnologias na análise morfométrica da alta bacia hidrográfica do ribeirão Santo Antônio, no município de Iporá-Goiás, Brasil”, GeoFocus (Artículos), n²1, p. 19-37. ISSN: 1578-5157 http://dx.doi.org/10.21138/GF.493

utilizado pela SANEAGO para abastecimento da cidade. Para seu posicionamento de forma mais precisa, sua locação foi feita inicialmente levando-se em conta a observação de imagens de alta resolução, disponíveis no programa Google Earth Pro, com posterior validação em campo para a coleta das coordenadas geográficas com uso de aparelho receptor GPS, modelo Monterra da Garmin.

Através do processamento das imagens TOPODATA, foram extraídas as variáveis altimétricas para confecção do mapa hipsométrico com intervalos altimétricos de 50 metros. Em seguida foi confeccionado também o mapa de declividade utilizando a classificação proposta pela Empresa Brasileira de Pesquisa Agropecuária (EMBRAPA, 1979), que sugere o emprego de seis classes de declividade para discriminar distintas feições do relevo, indicadas pela Tabela 1.

Tabela 1: Classes de declividades usadas conforme EMBRAPA (1979).

\begin{tabular}{cl}
\hline Declividade (\%) & \multicolumn{1}{c}{ Discriminação } \\
\hline $0-3$ & Relevo plano \\
\hline $3-8$ & Relevo suave ondulado \\
\hline $8-20$ & Relevo ondulado \\
\hline $20-45$ & Relevo forte ondulado \\
\hline $45-75$ & Relevo montanhoso \\
\hline$>75$ & Relevo forte montanhoso \\
\hline
\end{tabular}

Dentre os diversos parâmetros morfométricos descritos na literatura, foram selecionados os que melhor retratam a relação entre infiltração e escoamento superficial da água das chuvas, a ser abordada no presente trabalho, haja vista a intenção de analisar uma bacia de captação de água para abastecimento hídrico. Para a realização da análise morfométrica, foram obtidos quinze parâmetros por meio de análises topológicas (Tabela 2) e treze com uso de equações específicas junto ao programa QGIS (Tabela 3).

Tabela 2: Parâmetros obtidos a partir de análises topológicas

\begin{tabular}{lcc}
\hline \multicolumn{1}{c}{ Parâmetros } & Símbolo & Unidade \\
\hline Altimetria da bacia & $\mathrm{A}$ & $(\mathrm{m})$ \\
\hline Declividade da bacia & $\mathrm{D}$ & $(\%)$ \\
\hline Área da bacia & $\mathrm{A}$ & $(\mathrm{km})^{2}$ \\
\hline Perímetro da bacia & $\mathrm{P}$ & $(\mathrm{km})$ \\
\hline Ordem hierárquica dos canais & $\mathrm{O}$ & - \\
\hline Ponto mais alto da bacia & $\mathrm{P} 1 \mathrm{~b}$ & $(\mathrm{~m})$ \\
\hline Ponto mais baixo da bacia & $\mathrm{P} 2 \mathrm{~b}$ & $(\mathrm{~m})$ \\
\hline Comprimento do canal principal & $\mathrm{Ccp}$ & $(\mathrm{km})$ \\
\hline Altitude máxima do canal principal & $\mathrm{P} 1$ & $(\mathrm{~m})$ \\
\hline Altitude mínima do canal principal & $\mathrm{P} 2$ & $(\mathrm{~m})$ \\
\hline Número total de canais fluviais & $\mathrm{N}$ & - \\
\hline Número de canais fluviais de cada ordem & $\mathrm{Nu}$ & - \\
\hline Frequência dos canais de cada ordem & $\mathrm{Fo}$ & $(\%)$ \\
\hline Comprimento total dos canais fluviais & $\mathrm{Cc}$ & $(\mathrm{km})$ \\
\hline Distância vetorial do canal principal & $\mathrm{Ev}$ & $(\mathrm{km})$ \\
\hline
\end{tabular}


Borges de Moura, D. M., De Oliveira, R. M., De Oliveira, I. J., Ferreira Nascimento, D. T., Dos Santos Alves, W. (2018): "O uso de geotecnologias na análise morfométrica da alta bacia hidrográfica do ribeirão Santo Antônio, no município de Iporá-Goiás, Brasil”, GeoFocus (Artículos), no 21, p. 19-37. ISSN: 1578-5157 http://dx.doi.org/10.21138/GF.493

Tabela 3: Parâmetros morfométricos obtidos por meio de equações e suas fontes

\begin{tabular}{|c|c|c|}
\hline Índice morfométrico & Equação & Fonte \\
\hline Amplitude altimétrica máxima & $H m=P 1-P 2$ & Strahler (1952) \\
\hline Declividade média do canal principal & $S 1=\frac{100 H m}{L c p}$ & Villela e Mattos (1975) \\
\hline Índice de gradiente & $k=\frac{d H}{\operatorname{InL2}}-\operatorname{Inl} 1$ & Hack (1973) \\
\hline Densidade hidrográfica & $D h=\frac{N}{A}$ & Horton (1945) \\
\hline Densidade de drenagem & $D d=\frac{C t c}{A}$ & Horton (1945) \\
\hline Índice de circularidade & $I C=\frac{12,57 A}{P^{2}}$ & Muller (1953) \\
\hline Índice de rugosidade & $I r=H m * D d$ & Melton (1957) \\
\hline Sinuosidade do canal principal & $I s=\frac{L c p}{E v}$ & Schumm (1963) \\
\hline Coeficiente de compacidade & $K c=\frac{0,28 P}{\sqrt{A}}$ & Villela e Mattos (1975) \\
\hline Fator de forma & $K f=\frac{A}{L a^{2}}$ & Villela e Mattos (1975) \\
\hline Coeficiente de manutenção & $C m=\frac{1000}{D d}$ & Schumm (1956) \\
\hline Gradiente do canal principal & $G c p=\frac{A c p}{C c p}$ & Santos (2006) \\
\hline Razão de bifurcação & $R b=\frac{N u}{N u+1}$ & Horton (1945) \\
\hline
\end{tabular}

P1: maior cota da bacia (m), P2: menor cota da bacia (m), Lcp: comprimento em plano do curso de água principal $(\mathrm{km}), \mathrm{dH}$ : diferença altimétrica entre dois pontos do perfil, $\operatorname{lnL} 2$ e InL1: os logaritmos da distância da nascente ao ponto final e inicial do trecho considerado, $\mathrm{N}$ : quantidade de canais, A: área da bacia $\left(\mathrm{km}^{2}\right)$, Ctc: comprimento total dos canais $(\mathrm{km})$, P: perímetro da bacia $(\mathrm{km})$, Ev: distância vetorial do canal principal $(\mathrm{km})$, La: comprimento axial da bacia $(\mathrm{km})$, Rb: relação de bifurcação, Nu: número de segmentos de determinada ordem e $\mathrm{Nu}+1$ : número de segmentos da ordem imediatamente superior, Acp: Amplitude altimétrica do canal principal, Ccp: Comprimento do canal principal.

De modo a subsidiar a apresentação dos resultados, os parâmetros foram apresentados na forma de tabelas.

\section{Resultados e discussões}

Os parâmetros morfométricos são apresentados pela Tabela 4, representada a seguir, sendo informados o parâmetro e o resultado. 
Borges de Moura, D. M., De Oliveira, R. M., De Oliveira, I. J., Ferreira Nascimento, D. T., Dos Santos Alves, W. (2018): "O uso de geotecnologias na análise morfométrica da alta bacia hidrográfica do ribeirão Santo Antônio, no município de Iporá-Goiás, Brasil”, GeoFocus (Artículos), no 21, p. 19-37. ISSN: 1578-5157 http://dx.doi.org/10.21138/GF.493

Tabela 4: Resultados dos principais parâmetros analisados

\begin{tabular}{|c|c|c|}
\hline Símbolo & Parâmetro & Resultado \\
\hline Al & Altimetria da bacia & $557 \mathrm{~m}$ à $888 \mathrm{~m}$ \\
\hline Dc & Declividade da bacia & 0 à $45 \%$ \\
\hline A & Área da bacia & $127,062 \mathrm{~km}^{2}$ \\
\hline$P$ & Perímetro da bacia & $74,243 \mathrm{~km}$ \\
\hline $\mathrm{Ha}$ & Amplitude altimétrica da bacia & $331 \mathrm{~m}$ \\
\hline Сср & Comprimento do canal principal & $18,406 \mathrm{~km}$ \\
\hline Amax & Altitude máxima do canal principal & $767 \mathrm{~m}$ \\
\hline Amin & Altitude mínima do canal principal & $557 \mathrm{~m}$ \\
\hline Acp & Amplitude Altimétrica do canal principal & $210 \mathrm{~m}$ \\
\hline S1 & Declividade média do canal principal & $1,79 \%$ \\
\hline Gcp & Gradiente do canal principal & $11,4 \mathrm{~m} / \mathrm{km}$ \\
\hline $\mathrm{N}$ & Número total de canais fluviais & 236 \\
\hline $\mathrm{Dh}$ & Densidade Hidrográfica & 1,40 canais $/ \mathrm{km}^{2}$ \\
\hline Lt & Comprimento total dos canais fluviais & $161,497 \mathrm{~km}$ \\
\hline $\mathrm{Dd}$ & Densidade de Drenagem & $1,271 \mathrm{~km} / \mathrm{km}^{2}$ \\
\hline Ic & Índice de Circularidade & 0,289 adimensional \\
\hline Ir & Índice de rugosidade & 420,70 adimensional \\
\hline Ev & Distância vetorial do canal principal & $12,917 \mathrm{~km}$ \\
\hline Is & Sinuosidade do canal principal & $1,424 \mathrm{~km} / \mathrm{km}$ \\
\hline $\mathrm{Kc}$ & Coeficiente de compacidade & 1,84 adimensional \\
\hline Kf & Fator de forma & 0,37 adimensional \\
\hline $\mathrm{Cm}$ & Coeficiente de manutenção & $786,77 \mathrm{~m}^{2} / \mathrm{m}$ \\
\hline $\mathrm{Fr}$ & Frequência de canais & $\begin{array}{l}1^{\mathrm{a}} \text { ordem } 75,42 \% \\
2^{\mathrm{a}} \text { ordem } 17,37 \% \\
3^{\mathrm{a}} \text { ordem } 5,50 \% \\
4^{\mathrm{a}} \text { ordem } 1,27 \% \\
5^{\mathrm{a}} \text { ordem } 0,42 \%\end{array}$ \\
\hline $\mathrm{Rb}$ & Relação de bifurcação & $\begin{array}{l}1^{\mathrm{a}} \text { ordem }-4,34 \\
2^{\mathrm{a}} \text { ordem }-3,15 \\
3^{\mathrm{a}} \text { ordem }-4,33 \\
4^{\mathrm{a}} \text { ordem }-3,00\end{array}$ \\
\hline
\end{tabular}


Borges de Moura, D. M., De Oliveira, R. M., De Oliveira, I. J., Ferreira Nascimento, D. T., Dos Santos Alves, W. (2018): "O uso de geotecnologias na análise morfométrica da alta bacia hidrográfica do ribeirão Santo Antônio, no município de Iporá-Goiás, Brasil”, GeoFocus (Artículos), no 21, p. 19-37. ISSN: 1578-5157 http://dx.doi.org/10.21138/GF.493

\subsection{Altimetria da bacia}

As faixas altimétricas foram classificadas entre cotas com equidistância de 50 metros, conforme pode ser observado na Figura 3.

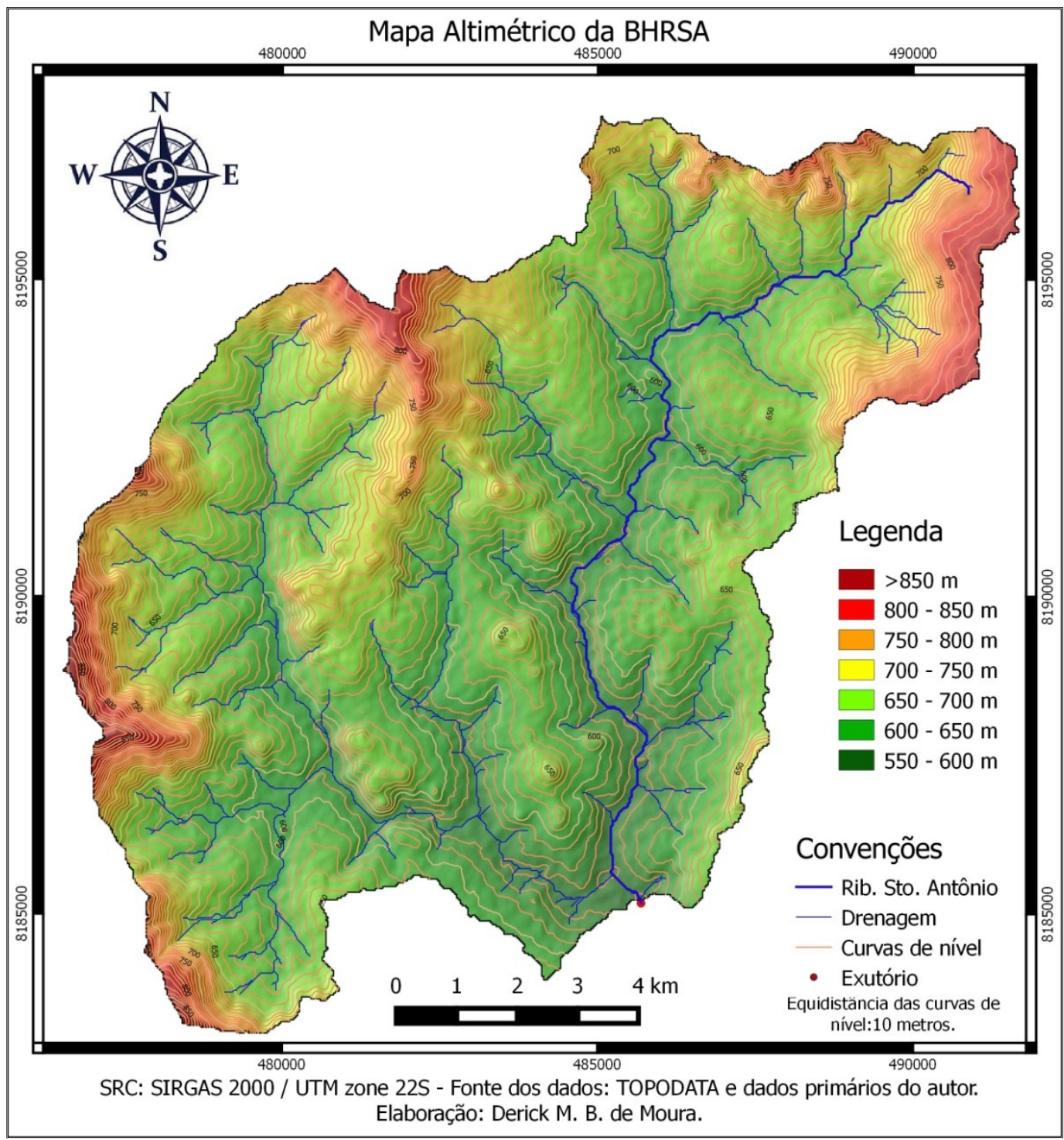

Figura 3: Altimetria da BHRSA

A observação dos dados de altimetria da bacia mostra uma amplitude de 331 metros, variando entre a cota mínima de 557 e a máxima de 888 metros. Quase metade da área da bacia hidrográfica encontra-se entre as cotas de 600 e 650 metros. E se somados os intervalos de 550 a 650 , chega-se a $2 / 3$ da área total. Portanto, apenas um terço da área da bacia apresenta cotas acima de $650 \mathrm{~m}$ de altitude, conforme indicado pela Figura 4 e Tabela 5. 
Borges de Moura, D. M., De Oliveira, R. M., De Oliveira, I. J., Ferreira Nascimento, D. T., Dos Santos Alves, W. (2018): "O uso de geotecnologias na análise morfométrica da alta bacia hidrográfica do ribeirão Santo Antônio, no município de Iporá-Goiás, Brasil”, GeoFocus (Artículos), no 21, p. 19-37. ISSN: 1578-5157 http://dx.doi.org/10.21138/GF.493

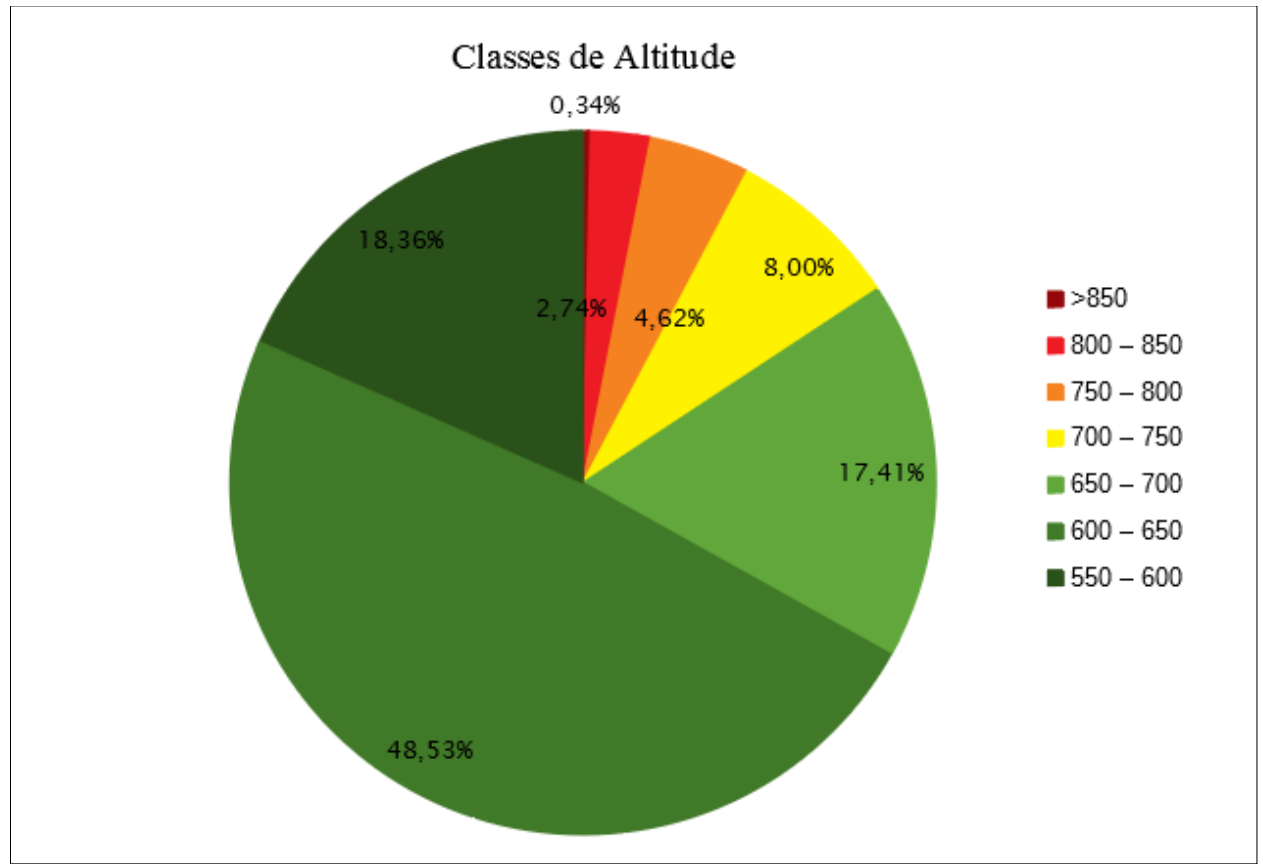

Figura 4: Distribuição das classes de Altitude (m)

Tabela 5: Distribuição das classes de Altitude

\begin{tabular}{cc}
\hline Classes de Atitude (m) & Área $\left(\mathbf{k m}^{\mathbf{2}}\right)$ \\
\hline$>850$ & 0,427 \\
\hline $800-850$ & 3,486 \\
\hline $750-800$ & 5,870 \\
\hline $700-750$ & 10,169 \\
\hline $650-700$ & 22,121 \\
\hline $600-650$ & 61,667 \\
\hline $550-600$ & 23,323 \\
\hline Total & 127,062 \\
\hline
\end{tabular}

\subsection{Declividade da bacia}

A declividade da bacia e o gradiente do curso d'água principal também são características que afetam diretamente o tempo de viagem da água ao longo do sistema. O tempo de concentração de uma bacia diminui com o aumento da declividade (Tucci, 1998). A declividade tem como finalidade demonstrar as inclinações de uma superfície em relação a um eixo horizontal. Neste estudo, a declividade foi gerada em porcentagens, tendo sido obtidas faixas até a quarta classe de padrões de inclinação do relevo, conforme a classificação da EMBRAPA (1979): plano, de 0 a $3 \%$; suave ondulado, de 3 a $8 \%$; ondulado, de 8 a $20 \%$; e forte ondulado, de 20 a $45 \%$.

Como percebe-se pelas figuras 5 e 6, e pela tabela 6, predomina na área em estudo o relevo variando de suave ondulado a ondulado, sendo que a classe suave ondulado ( 3 a $8 \%$ de declividade) ocorre em pouco mais de $63 \%$ da BHRSA, e, se somada à classe de relevo ondulado, totaliza $84 \%$ da área da bacia. 
Borges de Moura, D. M., De Oliveira, R. M., De Oliveira, I. J., Ferreira Nascimento, D. T., Dos Santos Alves, W. (2018): "O uso de geotecnologias na análise morfométrica da alta bacia hidrográfica do ribeirão Santo Antônio, no município de Iporá-Goiás, Brasil”, GeoFocus (Artículos), no 21, p. 19-37. ISSN: 1578-5157 http://dx.doi.org/10.21138/GF.493

Mapa das Classes de Declividade da Bacia Hidrográfica do Ribeirão Santo Antônio

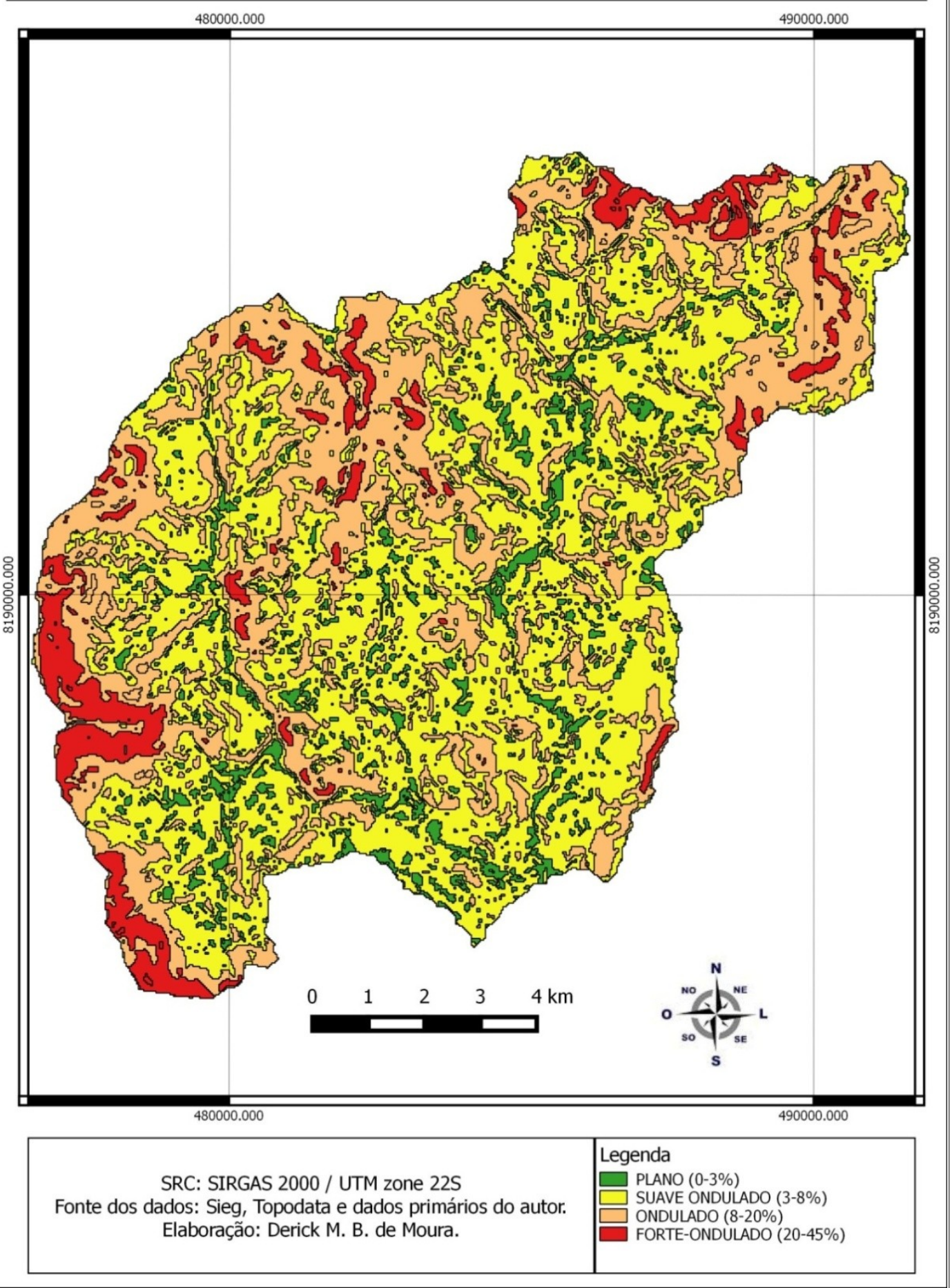

Figura 5: Mapa das faixas de declividade da BHRSA 
Borges de Moura, D. M., De Oliveira, R. M., De Oliveira, I. J., Ferreira Nascimento, D. T., Dos Santos Alves, W. (2018): "O uso de geotecnologias na análise morfométrica da alta bacia hidrográfica do ribeirão Santo Antônio, no município de Iporá-Goiás, Brasil”, GeoFocus (Artículos), no 21, p. 19-37. ISSN: 1578-5157 http://dx.doi.org/10.21138/GF.493

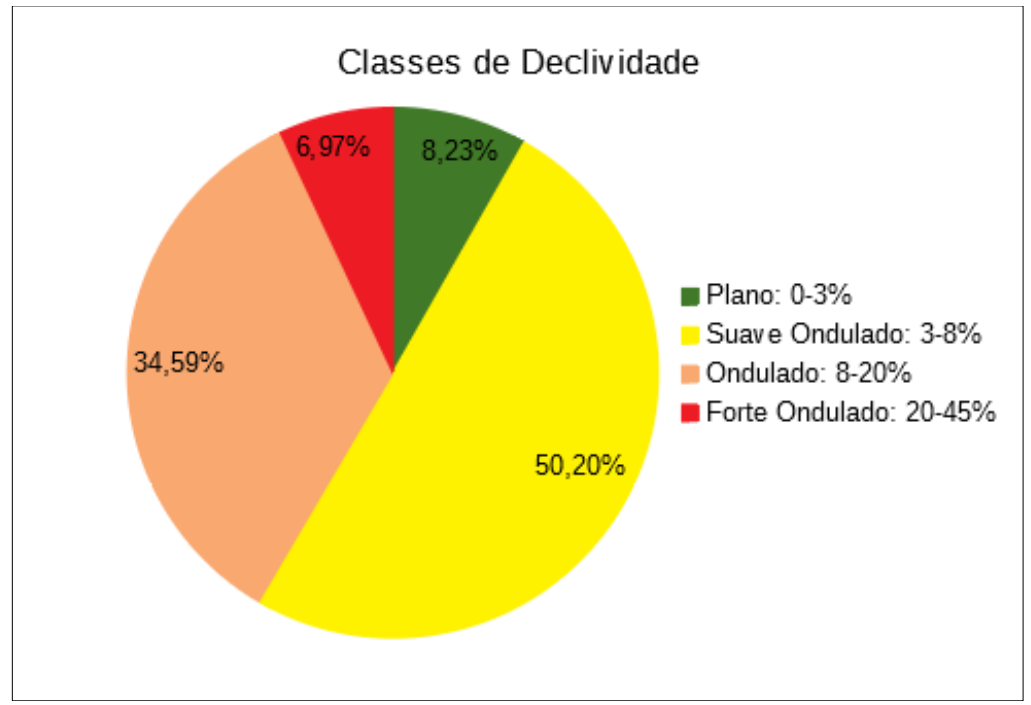

Figura 6: Distribuição das classes de declividade

Tabela 6: Classes de declividade da BHRSA

\begin{tabular}{lcc}
\hline \multicolumn{1}{c}{ Tipo de relevo } & Declividade (\%) & Área $\left.\mathbf{( k m}^{\mathbf{2}}\right)$ \\
\hline Plano & 0 a 3 & 10,487 \\
\hline Suave ondulado & 3 a 8 & 63,944 \\
\hline Ondulado & 8 a 20 & 44,059 \\
\hline Forte ondulado & 20 a 45 & 8,880 \\
\hline & Total & 127,062 \\
\hline
\end{tabular}

3.3 Ordem hierárquica dos canais

Segundo Strahler (1957), a rede hidrográfica se divide em segmentos individuais de rio, estando cada segmento situado entre duas confluências. O ordenamento dos rios é realizado a partir da atribuição da ordem 1 aos rios que não possuem tributários, ou seja, são nascentes; a ordem 2 é atribuída ao rio formado pelo encontro de dois rios de primeira ordem; este rio, por sua vez, só se torna de terceira ordem ao encontrar outro segmento de segunda ordem. A confluência de rios de ordens diferentes não altera o grau de ordenamento. A hierarquia fluvial indica o grau de ramificação da bacia, sendo importante na determinação da velocidade com que a água escoa até o exutório. Assim, a descarga aumenta em relação exponencial com o aumento da ordem hierárquica do canal (Souza, 2005). A BHRSA possui uma hierarquia de drenagem de até $5^{\text {a }}$ ordem, como podemos notar na figura 7 . 
Borges de Moura, D. M., De Oliveira, R. M., De Oliveira, I. J., Ferreira Nascimento, D. T., Dos Santos Alves, W. (2018): "O uso de geotecnologias na análise morfométrica da alta bacia hidrográfica do ribeirão Santo Antônio, no município de Iporá-Goiás, Brasil”, GeoFocus (Artículos), no 21, p. 19-37. ISSN: 1578-5157 http://dx.doi.org/10.21138/GF.493

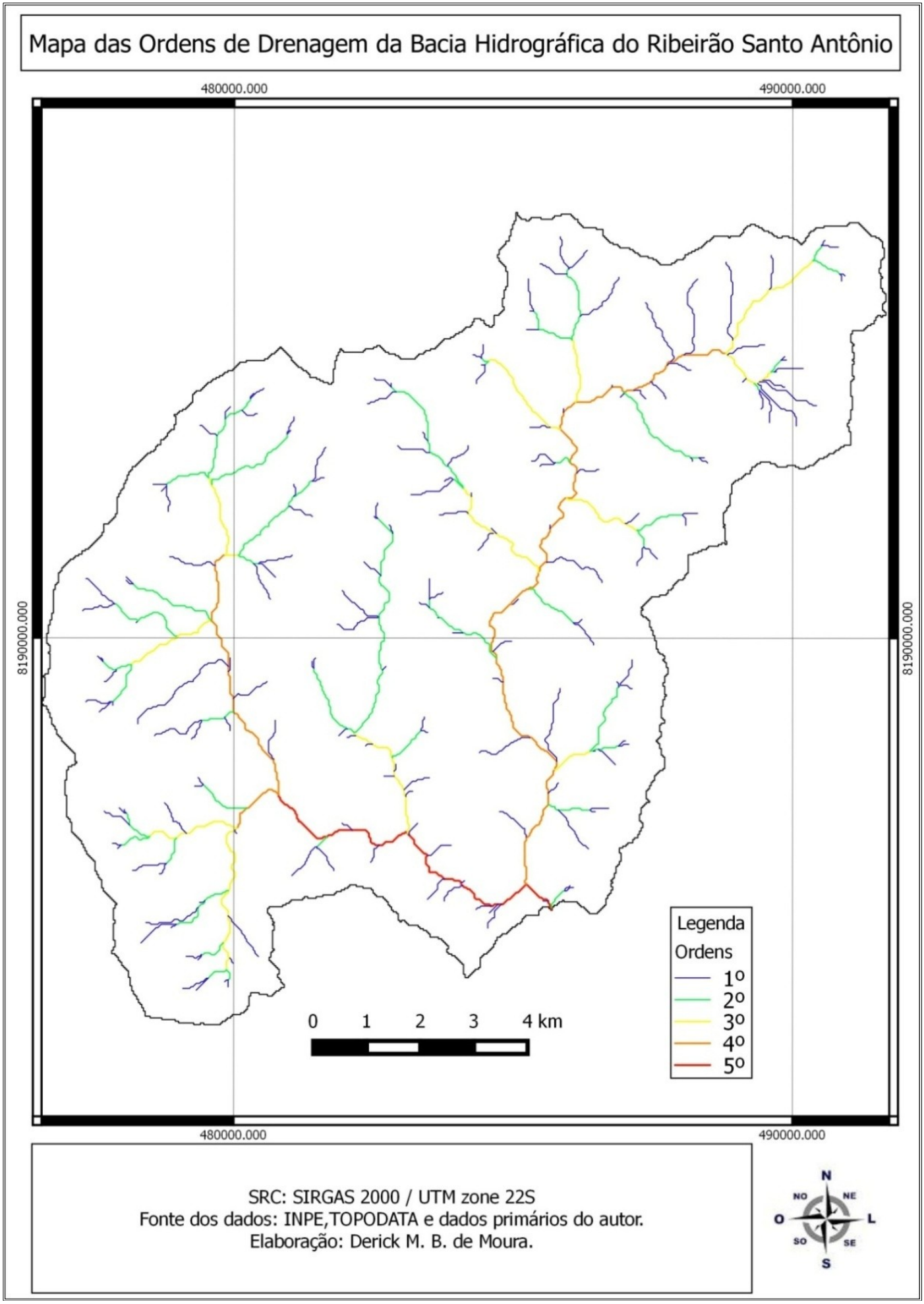

Figura 7: Mapa das Ordens de drenagens da BHRSA, conforme Strahler (1957) 
Borges de Moura, D. M., De Oliveira, R. M., De Oliveira, I. J., Ferreira Nascimento, D. T., Dos Santos Alves, W. (2018): "O uso de geotecnologias na análise morfométrica da alta bacia hidrográfica do ribeirão Santo Antônio, no município de Iporá-Goiás, Brasil”, GeoFocus (Artículos), no 21, p. 19-37. ISSN: 1578-5157 http://dx.doi.org/10.21138/GF.493

\section{4 Área da bacia}

Segundo Strahler (1957), a área da bacia é a área total projetada sobre um plano horizontal da área de contribuição de escoamento para a determinada ordem, incluindo todos os tributários de ordem inferior. Representa a área de captação disponível e, portanto, quanto maior a área, maior poderá ser o volume de precipitação entrando no sistema da bacia hidrográfica. Schumm (1956), afirma que a área da bacia cresce exponencialmente com a ordem dos canais. Além disso, quanto maior a área da bacia, maior o número de canais de $1^{\mathrm{a}}$ ordem, e maior o perímetro da bacia (Souza, 2005). A área da BHRSA é de $127,062 \mathrm{~km}^{2}$, sendo considerada uma bacia mediana, para a finalidade de abastecimento hídrico de uma cidade cuja população urbana foi registrada em 29.489 habitantes no ano de 2017.

Nos âmbito do Macrozoneamento Ecológico e Econômico do Estado de Goiás (MacroZAEE), foram mapeadas as áreas das bacias hidrográficas de captação de água para abastecimento público dos municípios do Estado. Nesse mapeamento verifica-se bacias hidrográficas de abastecimento de outras cidades com áreas maiores que da BHRSA. Como exemplo pode-se citar a cidade de Diorama (GO), que é a cidade vizinha com a bacia hidrográfica mais próxima. A bacia hidrográfica de abastecimento da cidade de Diorama (GO) é a Bacia do Rio dos Bois, que possui $178,91 \mathrm{~km}^{2}$ de área, sendo que a cidade só possui a população urbana de 1.506 habitantes no ano de 2017. Essa relação deixa a cidade de Diorama (GO) com uma segurança hídrica maior. Dessa forma pode-se perceber que a consideração do tamanho da área da bacia de abastecimento está relacionado com a demanda de água que a população urbana produz.

\subsection{Perímetro da bacia}

O perímetro da bacia é tido com base na projeção horizontal da linha que contorna o divisor de águas (Souza, 2005). No caso da BHRSA, o perímetro é de 74,243 km.

3.6 Número de canais de $1^{\mathrm{a}}$ ordem

Esse indicador representa a quantidade das nascentes, refletindo as áreas de recarga dos canais de drenagem. Em tese, deveriam ser, majoritariamente, áreas de vegetação mais densa. E também estão associadas às maiores elevações do relevo. Na BHRSA existem 178 canais fluviais de $1^{\mathrm{a}}$ ordem, indicando o mesmo número de nascentes.

\subsection{Comprimento do canal principal}

O comprimento da drenagem principal é uma característica fundamental da bacia hidrográfica porque está relacionado ao tempo de viagem da água ao longo de todo o sistema. $\mathrm{O}$ tempo de viagem da gota de água da chuva que atinge a região mais remota da bacia até o momento em que atinge o exutório é chamado de tempo de concentração da bacia (Tucci, 2002). O comprimento do canal principal da BHRSA é de $18,406 \mathrm{~km}$.

\subsection{Comprimento vetorial do canal principal}

Segundo Horton (1945), o comprimento vetorial do canal principal é a distância, em linha reta, entre a nascente e a foz do canal principal. Tem relação diretamente proporcional com a área e o perímetro da bacia. O comprimento vetorial do ribeirão Santo Antônio é de 12,917 km. Esse comprimento demonstra uma diferença de $5,48 \mathrm{~km}$ em relação ao comprimento real do canal principal, demonstrando que o canal principal não é muito meandrante.

3.9 Gradiente do canal principal 
Borges de Moura, D. M., De Oliveira, R. M., De Oliveira, I. J., Ferreira Nascimento, D. T., Dos Santos Alves, W. (2018): "O uso de geotecnologias na análise morfométrica da alta bacia hidrográfica do ribeirão Santo Antônio, no município de Iporá-Goiás, Brasil”, GeoFocus (Artículos), no 21, p. 19-37. ISSN: 1578-5157 http://dx.doi.org/10.21138/GF.493

O gradiente do canal principal é a relação entre sua amplitude altimétrica e o seu comprimento. Está relacionado com energia potencial do rio, e, consequentemente, seu poder erosivo (Santos, 2006). É um bom indicador da capacidade de transporte de sedimentos de um rio. Quanto maior for o gradiente do canal principal maior será a capacidade de transporte de um rio, pois maior é a sua declividade. Na BHRSA o gradiente do canal principal é de $11,40 \mathrm{~m} / \mathrm{km}$, demonstrando a fase jovial do canal principal, e seu alto poder erosivo.

\section{$3.10 \quad$ Fator de forma}

$\mathrm{O}$ fator de forma relaciona a forma da bacia com um retângulo. Valores de fator de forma menores que 0,50 significam bacias não sujeitas a inundações; valores entre 0,50 e 0,75 representam tendência mediana, enquanto valores entre 0,75 e 1,0 sugerem bacias sujeitas a inundações (Vilella e Mattos, 1975). O fator de forma da BHRSA tem o valor 0,37, significando que, de maneira geral, a bacia não está propensa a inundações.

\subsection{1 Índice de circularidade}

De acordo com Christofoletti (1974), o índice de circularidade foi proposto com o objetivo de eliminar a subjetividade na caracterização da forma da bacia. Para o cálculo do Índice de circularidade é necessário obter o valor da área do círculo de perímetro igual ao da bacia em questão. $\mathrm{O}$ índice de circularidade apresenta valores entre 0 e 1 , sendo que quanto mais próximo da unidade, mais próxima da forma circular será a bacia, sendo também mais propensa ao desenvolvimento de cheias. Valores menores que 0,51 correspondem a bacias de formato alongado, que favorece o escoamento; valores maiores que 0,51 correspondem a bacias de formato circular, que favorecem o desenvolvimento de inundações. Já valores iguais a 0,51 significam escoamento moderado e pequena probabilidade de cheias. O índice de circularidade da BHRSA é de 0,28, representando uma bacia de formato alongado, que favorece o escoamento superficial das águas.

\subsection{2 Índice de rugosidade}

O índice de rugosidade relaciona a disponibilidade do escoamento hídrico superficial com seu potencial erosivo, expresso pela declividade média. Quanto maior for esse índice, maior será o risco de degradação da bacia devido ao predomínio de vertentes íngremes e longas. Trata-se de um índice adimensional que corresponde à diferença altimétrica entre a foz e a maior altitude situada num determinado ponto da área da bacia, que indica o desnível médio da bacia hidrográfica (Melton, 1957). O índice de rugosidade da BHRSA é de 420,70 m, sendo considerado um valor alto quando comparado com outras bacias e que demonstra um relevo acidentado e bem dissecado, ou seja, consideravelmente erosionado.

\subsection{Densidade de drenagem}

A densidade de drenagem relaciona o comprimento total dos rios com a área da bacia hidrográfica. É uma das variáveis morfométricas mais importantes, que representa o grau de dissecação topográfica da bacia. Este parâmetro expressa a quantidade de canais disponíveis para o escoamento, de forma que quanto mais canais presentes na bacia, mais rápido a água precipitada atinge o exutório. Depende de fatores como precipitação, declividade das vertentes, tipo de solo, geologia, e cobertura vegetal, sendo a resposta ao ajuste entre a precipitação e os outros fatores. Além disso, a densidade de drenagem tem influência sobre o escoamento e o transporte de sedimentos dentro da bacia hidrográfica (Christofoletti, 1999). Pode-se classificar a densidade de drenagem como muito baixa para valores menores que $0,50 \mathrm{~km} / \mathrm{km}^{2}$, mediana entre 0,50 e 2,00 $\mathrm{km} / \mathrm{km}^{2}$, alta entre 2,01 e $3,50 \mathrm{~km} / \mathrm{km}^{2}$ e muito alta para valores acima de $3,50 \mathrm{~km} / \mathrm{km}^{2}$ (Beltrame, 1994). A densidade de drenagem da BHRSA é de $1,27 \mathrm{~km} / \mathrm{km}^{2}$, representando uma densidade mediana. 


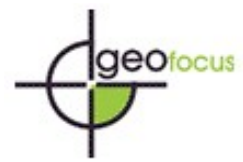

Borges de Moura, D. M., De Oliveira, R. M., De Oliveira, I. J., Ferreira Nascimento, D. T., Dos Santos Alves, W. (2018): "O uso de geotecnologias na análise morfométrica da alta bacia hidrográfica do ribeirão Santo Antônio, no município de Iporá-Goiás, Brasil”, GeoFocus (Artículos), no 21, p. 19-37. ISSN: 1578-5157 http://dx.doi.org/10.21138/GF.493

\subsection{Densidade hidrográfica}

Constitui a relação existente entre o número de canais e a área da bacia hidrográfica. Destina-se a comparação da frequência de cursos de água existentes em uma área, de tamanho padrão. Bacias com baixa densidade hidrográfica são as que possuem valores de até 0,5 canais $/ \mathrm{km}^{2}$, mediana com valores de até 1,5 canais $/ \mathrm{km}^{2}$, boa com até 2,5 canais $/ \mathrm{km}^{2}$, muito boa até 3,5 canais $/ \mathrm{km}^{2}$ e excepcionais maiores que 3,5 canais $/ \mathrm{km}^{2}$ (Horton, 1945). A densidade hidrográfica da BHRSA é de 1,4 canais $/ \mathrm{km}^{2}$, o que representa que existem 1,4 canais de drenagens a cada $1 \mathrm{~km}^{2}$ na bacia, sendo considerada uma bacia com um valor de densidade hidrográfica mediana.

\subsection{Coeficiente de manutenção}

Representa a área mínima necessária para manutenção de um metro de escoamento. Este parâmetro corresponde à área necessária para formação de um canal com fluxo perene. Entretanto, sua expressão matemática demonstra que ele nada mais é do que a razão inversa da densidade de drenagem da bacia (Dd). Schumm (1956, citado em Christofoletti, 1974) considera esse parâmetro um dos mais importantes para a realização de análises hidromorfológicas. Na BHRSA, o coeficiente de manutenção é $786,77 \mathrm{~m}^{2} / \mathrm{m}$, ou seja, são necessários $786 \mathrm{~m}^{2}$ para formar um metro de canal com fluxo perene. Sendo o coeficiente de manutenção a razão inversa da densidade de drenagem, ele também tem um valor mediano na bacia.

\subsection{Coeficiente de compacidade}

De acordo com Vilela e Mattos (1975), o coeficiente de compacidade pode ser interpretado como a relação entre o perímetro da bacia e a circunferência de área igual à da bacia. Quanto mais irregular for à bacia, maior será o coeficiente de compacidade. A tendência de uma bacia hidrográfica sofrer cheias será tanto maior quanto mais próximo de 1.0 for o coeficiente de compacidade, ou seja, quanto mais próximo de um círculo for à forma da bacia. Na BHRSA o coeficiente de compacidade é de 1,84 representando que a bacia, de maneira geral, não é propensa a cheias.

\subsection{Frequência de canais de cada ordem}

Refere-se à frequência relativa de canais de cada ordem pelo número de canais totais. Um número elevado de canais de $1^{\mathrm{a}}$ ordem está relacionado com o tempo decorrido entre a precipitação máxima e a descarga máxima no canal principal (Souza, 2005). As frequências de canais de cada ordem são:

Frequência de canais de $1^{\mathrm{a}}$ ordem: $75,42 \%$

Frequência de canais de $2^{\mathrm{a}}$ ordem: $17,37 \%$

Frequência de canais de $3^{\mathrm{a}}$ ordem: $5,50 \%$

Frequência de canais de $4^{\mathrm{a}}$ ordem: $1,27 \%$

Frequência de canais de $5^{\mathrm{a}}$ ordem: $0,42 \%$

O resultado mostra uma elevada frequência de canais de $1^{\mathrm{a}}$ ordem, em consequência um menor tempo entre a precipitação e a descarga no canal principal. 
Borges de Moura, D. M., De Oliveira, R. M., De Oliveira, I. J., Ferreira Nascimento, D. T., Dos Santos Alves, W. (2018): "O uso de geotecnologias na análise morfométrica da alta bacia hidrográfica do ribeirão Santo Antônio, no município de Iporá-Goiás, Brasil”, GeoFocus (Artículos), n²1, p. 19-37. ISSN: 1578-5157 http://dx.doi.org/10.21138/GF.493

Representa a relação entre o número total de segmentos de uma certa ordem e o número total de segmentos (canais, rios) de ordem imediatamente superior. A relação de bifurcação varia entre 2, para bacias planas a suave onduladas, 3, para bacias montanhosas, e 4 para bacias altamente dissecadas (Horton, 1945). A Relação de bifurcação encontrada na BHRSA foi de:

Canais de $1^{\mathrm{a}}$ ordem $=4,34$

Canais de $2^{\mathrm{a}}$ ordem $=3,15$

Canais de $3^{\mathrm{a}}$ ordem $=4,33$

Canais de $4^{\mathrm{a}}$ ordem $=3$

A proximidade com o valor 4 indica que a bacia é altamente dissecada, favorecendo no escoamento superficial das águas.

\subsection{9 Índice de sinuosidade do canal principal}

Parâmetro apresentado por Schumm (1963) e descrito por Alves e Castro (2003) como sendo uma das formas de representar a influência da carga sedimentar, a compartimentação litológica e estrutural. A equação utilizada no cálculo é dada por: Lcp dividido por Ev em que, Lcp é o comprimento em plano do curso de água principal e Ev equivalente vetorial médio em linha reta do canal principal, sendo que os valores próximos a 1 indicam elevado controle estrutural ou alta energia e valores acima de 2 indicam baixa energia, sendo os valores intermediários relativos a formas transicionais entre canais retilíneos e meandrantes. $\mathrm{O}$ índice de sinuosidade do canal principal da BHRSA é de 1,42 sendo mais próximo de 1, indicando a fase juvenil do canal principal e seu considerável poder de escoamento e carreamento de sedimentos.

Todos os parâmetros morfométricos analisados corroboram para um entendimento de que a morfometria da bacia, de maneira geral, é propensa ao escoamento superficial das águas e desfavorável à infiltração. A bacia é bem drenada, possui um relevo com dissecação forte e curto tempo de descarga de água no canal principal, o que significa que quando a chuva cai sobre a bacia, leva pouco tempo para o escoamento superficial das águas atingirem o canal principal e o exutório. Da mesma forma, o comprimento do canal principal é considerado como um trecho curto. A área da bacia é considerada mediana, por se tratar de uma bacia que tem a função de fornecer água para o abastecimento da cidade cuja população urbana é de 29.489 habitantes (IBGE, 2017).

\section{Considerações finais}

O uso de geotecnologias para análise morfométrica da BHRSA facilitou o trabalho e mostrou-se uma ferramenta eficaz. O uso do software QGIS proporcionou um trabalho de baixo custo por ser um software livre. As imagens SRTM disponibilizadas pelo TOPODATA do INPE também contribuíram para a qualidade final do trabalho e para o baixo custo operacional, por serem gratuitas. As ferramentas geotecnológicas demonstram que é possível executar um estudo de qualidade, rápido e prático.

Os resultados do trabalho mostraram que a alta bacia hidrográfica do ribeirão Santo Antônio não é propensa a inundações, possuindo grande facilidade no escoamento superficial das águas, pois é bem drenada, com dissecação e declividade que favorece a velocidade do escoamento hídrico. Contudo, é suscetível a erosões e carreamento de sedimentos, além de desfavorecer à recarga hídrica. Dessa forma, o uso do solo sem observação dos critérios geomorfológicos poderá contribuir para agravar o problema de maior velocidade no escoamento superficial, em consequência reduzir ainda mais a recarga hídrica do lençol freático. Desse modo fica exposta a necessidade de um planejamento ambiental minucioso para evitar a perda das águas pluviais sem 
Borges de Moura, D. M., De Oliveira, R. M., De Oliveira, I. J., Ferreira Nascimento, D. T., Dos Santos Alves, W. (2018): "O uso de geotecnologias na análise morfométrica da alta bacia hidrográfica do ribeirão Santo Antônio, no município de Iporá-Goiás, Brasil”, GeoFocus (Artículos), no 21, p. 19-37. ISSN: 1578-5157 http://dx.doi.org/10.21138/GF.493

que essas tenham tempo de infiltrarem nos solos e recarregarem o lençol freático que sustentará o abastecimento das nascentes e em consecutivo toda a rede fluvial até o ponto exutório, que é o local de captação da água da bacia para abastecimento público da cidade.

A análise morfométrica é uma metodologia que tem por objetivo estabelecer comparações matemáticas entre bacias hidrográficas. Tendo em vista esse pressuposto, o trabalho se mostrou útil, pois os dados hidromorfológicos eram ausentes para a bacia em estudo, o que teve grande relevância em se tratando de uma bacia que é fornecedora de água para abastecimento da cidade. Entretanto, para obter um diagnóstico ambiental completo, deve ser analisada em conjunto com outros métodos. Deve ser observado o uso do solo e a cobertura vegetal na bacia, uma vez que locais onde houver maior declividade e presença de atividades agrícolas devem ser implementadas técnicas conservacionistas de manejo e uso do solo, para que amenizem o escoamento superficial das águas e favoreçam a infiltração, de mesma forma, evitando a erosão dos solos e das águas, que seria prejudicial para os agricultores e para o abastecimento hídrico da cidade.

\section{Referências bibliográficas}

ALVES, J. M. P.; CASTRO, P. T. A. (2003): Influência das feições geológicas na morfologia da bacia do rio do Tanque (MG) baseada no estudo de parâmetros morfométricos e análise de padrões de lineamentos. Revista Brasileira de Geociências, São Paulo, v. 33, n. 2, p. 117-124.

BELTRAME, A. da V. (1994): Diagnóstico do meio físico de bacias hidrográficas: modelo e aplicação. EDUFSC. Florianópolis.

CHRISTOFOLETTI, A. (1974): A análise de bacias hidrográficas. In: CHRISTOFOLETTI, Antonio. Geomorfologia. Edgard Blücher, EDUSP. São Paulo.

CHRISTOFOLETTI, A. (1980): Geomorfologia. 2. ed. Edgard Blücher, São Paulo. 188p.

CHRISTOFOLETTI, A. (1999): Modelagem de sistemas ambientais. Edgard Blücher, São Paulo, 186p.

EMBRAPA. (1979): Serviço Nacional de Levantamento e Conservação de Solos (Rio de Janeiro, RJ). Súmula da 10. Reunião Técnica de Levantamento de Solos. Rio de Janeiro, 83p

HACK, J. T. (1973): Stream profile analysis and stream gradient index. J. Res. US Geol. Survey, v. 1, n.4, p. 421-429.

HORTON, R. E. (1945): Erosional development of streams and their drainage basins: hydrophysical approach to quantitative morphology. Bulletin of the Geological Society of America, v. 56, p. 275-370.

IBGE. (2015): Instituto Brasileiro de Geografia e Estatística. Informações Estatísticas Municipais. Disponível em: <www.ibge.gov.br/>. Acesso em: 15 Jan. 2015.

IMB (2014): Instituto Mauro Borges de Estatística e Estudos Socioeconômicos. Estatísticas municipais. Disponível em: http://www.imb.go.gov.br/ Acesso em: 03 de jul 2015.

KÖEPPEN, W. (1948): Climatologia: con un Estudio de los Climas de la Tierra. Fundo de Cultura Econômica, México. p. 46-70.

MELTON, M. A. (1957): An analysis of the relations among elements of climate, surface properties, and geomorphology. Columbia University, New York. 
Borges de Moura, D. M., De Oliveira, R. M., De Oliveira, I. J., Ferreira Nascimento, D. T., Dos Santos Alves, W. (2018): "O uso de geotecnologias na análise morfométrica da alta bacia hidrográfica do ribeirão Santo Antônio, no município de Iporá-Goiás, Brasil”, GeoFocus (Artículos), n²1, p. 19-37. ISSN: 1578-5157 http://dx.doi.org/10.21138/GF.493

MOURA, D. M. B.; OLIVEIRA, R. M.; ALVES, W. S. (2017): Avaliação da disponibilidade e demanda hídrica do Ribeirão Santo Antônio no ano de 2016, visando a segurança hídrica da cidade de Iporá (GO). In: Diversos olhares geográficos - Elucidações para fenômenos da natureza no processo de apropriação dessa natureza a partir da microrregião de Iporá. Goiânia. Kelps.

MÜLLER V. C. (1953): A quantitative geomorphology study of drainage basin characteristic in the Clinch Mountain Area, New York, Virginia and Tennesse. Columbia University, New York.

PFAFSTETTER, O. (1989): Classificação de bacias hidrográficas - Metodologia de codificação. Departamento Nacional de Obras de Saneamento (DNOS), Rio de Janeiro RJ, p. 19.

QGIS Development Team (2018). QGIS Geographic Information System. Open Source Geospatial Foundation Project. http://qgis.osgeo.org.

SANTOS, G. F. (2006): Geomorfologia. In: AUMOND, J. J. FRANK, B. (org.). Atlas da Bacia do Itajaí: Formação, Recursos Naturais e Ecossistemas. Edifurb. Blumenau.

SCHUMM, S. A. (1963): Sinuosity of alluvial rivers on the great plains. Geological Society of America Bulletin 74 (9): 1089-1100.

SCHUMM, S. A. (1956): Evolution of drainage systems and slopes In badlands at Perth Amboy. Geological Society of America Bulletin, N. Jersey, v.67, p.597-646.

SOUSA, F. A de. (2013): A contribuição dos solos originados sobre granitos e rochas alcalinas na condutividade hidráulica, na recarga do lençol freático e na suscetibilidade erosiva - um estudo de caso na alta bacia hidrográfica do rio dos bois em iporá (GO).(Tese de doutorado). Uberlândia. UFU, Programa de Pesquisa e Pós-graduação em geografia. 207p.

SOUZA, C. R. de G. (2005): Suscetibilidade Morfométrica de Bacias de Drenagem ao Desenvolvimento de Inundações em Áreas Costeiras. Revista Brasileira de Geomorfologia, ano 6, n.1. pp 45-61.

STRAHLER, A. N. (1952): Hypsometric (area-altitude) analysis and erosional topography. Geological Society of America Bulletin. 63(11): 1117-1142.

STRAHLER, A. N. (1957): Quatitative analysis of watershed geomophology. Transactions of the American Geophysical Union. v. 38, n. 6, p. 913-920.

TOPODATA. (2015): Banco de Dados Geomorfométricos do Brasil. Folha 16S525. Altitude. Disponível em: < www.webmapit.com.br/inpe/topodata/>. Acesso em: 15 jul. 2015.

TUCCI, C. E. M.; MENDES, C. A. (2006): Avaliação ambiental integrada de bacia hidrográfica. Ministério do Meio Ambiente. Brasília.

TUCCI, C. E. M. (1998): Modelos Hidrológicos. Associação Brasileira de Recursos Hídricos. $1^{\text {a }}$ ed. Porto Alegre: Ed. Universidade / UFRGS.

TUCCI, C. E. M. (2002): Regionalização de vazões. Ed. Universidade / UFRGS.

VILLELA, S. ; MATTOS M. (1975): A. Hidrologia Aplicada. McGraw-Hill, São Paulo. 
